\title{
Temperature progression in a mixer ball mill
}

\author{
Robert Schmidt $^{1} \cdot$ H. Martin Scholze ${ }^{1}$ Achim Stolle ${ }^{1}$
}

Received: 23 June 2015/ Accepted: 7 March 2016/Published online: 22 April 2016

(c) The Author(s) 2016. This article is published with open access at Springerlink.com

\begin{abstract}
The influence of the operating frequency, the milling ball and grinding stock filling degree, the material of the milling balls and beakers, the milling ball diameter and the size of the milling beakers on the temperature increase inside the milling beakers in a mixer ball mill was investigated. These parameters influence the temperature progression and the equilibrium temperature of the system. The grinding stock filling degree with regard to the void volume in the milling ball package showed huge influence on the heating rate and the equilibrium temperature. In this context, the behavior of the temperature progression changes if the complete void volume is filled with the grinding stock.
\end{abstract}

Keywords Ball milling - Temperature measurement . Milling parameters

\section{Introduction}

Mechanochemistry using ball mills is a promising technique with applications in organic and inorganic chemistry as well as material sciences [1-4]. During ball milling, up to $80 \%$ of the energy that is generated in the mill is dissipated as heat [5]. This is why measurement and control of

Electronic supplementary material The online version of this article (doi:10.1007/s40090-016-0078-8) contains supplementary material, which is available to authorized users.

Achim Stolle

Achim.Stolle@uni-jena.de

$1 \quad$ Institute for Technical Chemistry and Environmental Chemistry (ITUC), Friedrich-Schiller University Jena, Lessingstr. 12, 07743 Jena, Germany the temperature in the ball mills is important, for example, if heat-sensitive products are formed that would be degraded, or side reactions that would be favored at high temperatures [6, 7]. Furthermore, liquefaction of organic substrates because of a temperature increase can diminish the energy transfer and may disturb the reaction [8].

Ball milling procedures are often referred to as "milling at room temperature" $[9,10]$. This term should be used carefully, as even within short milling times a temperature increase can be observed, if there are no precautions for temperature control. For example, it was shown that milling in a mixer ball mill (MBM) for $10 \mathrm{~min}$ with two milling balls in a $10 \mathrm{ml}$ beaker raised the temperature from 25 to $30{ }^{\circ} \mathrm{C}$, and Colacino and co-workers measured a temperature increase of approximately $14 \mathrm{~K}$ after $30 \mathrm{~min}$ milling in an MM200 mixer mill [6, 11]. McKissic et al. observed a temperature of $50{ }^{\circ} \mathrm{C}$ after $1 \mathrm{~h}$ milling in a Spex mixer mill and Takacs and McHenry reported milling ball temperatures of $66^{\circ} \mathrm{C}[12,13]$. Comparably higher temperatures can be reached in planetary ball mills (PBMs), where temperatures from 60 to $600{ }^{\circ} \mathrm{C}$ can be measured, depending on the type of PBM, the grinding stock, the grinding material and the filling degree $[5,13,14]$.

The temperature of the milling beaker is often determined on the surface of the milling beaker, which can be done for example with temperature data loggers $[12,15]$ or thermocouples $[13,16]$. However, the temperature on the surface is not necessarily the temperature inside the milling beaker, and a temperature difference between milling beaker and balls of $25 \mathrm{~K}$ was reported [13]. For determination of the milling balls temperature, calorimetric measurements can be performed [5, 13]. The Lamaty group developed a mathematical model for the prediction of the milling walĺs temperature. Experimental and simulated results (MBM MM200, operated at $30 \mathrm{~s}^{-1}$ with $10 \mathrm{ml}$ steel 
vessels) were in good accordance. The calculated temperature difference of the inner and outer side of the vessel was negligible [11].

Temperature control and more importantly temperature regulation in MBMs and PBMs can be challenging. One option is the integration of milling pauses to the milling cycle that allow a cooling down of the milling beakers, but also increase the total reaction time [10, 17, 18]. Technical solutions for a temperature-controlled milling are: cryogenic milling, where the beakers are cooled with liquid nitrogen [19]; water cooling of the vessels [5] and of the milling beaker holder [20]; (forced) air cooling [21]; use of heating tapes [22]; the application of double-walled milling beakers, which are equipped with an inlet and outlet for a circulating liquid that can be tempered by a thermostat [23-25].

In this study, the influence of milling parameters on the temperature progression in a MBM was investigated.

\section{Methods}

All chemicals were purchased from Sigma Aldrich or Alfa Aesar and used as received. The reactions were accomplished in a Retsch MM400 Mixer Mill. If not stated otherwise, milling beakers made of stainless or tempered steel with a volume of $35 \mathrm{~mL}$ and steel milling balls with a diameter of $5 \mathrm{~mm}$ were used. The temperature was measured with a K-type thermocouple.

The temperature was determined inside of the milling beaker ( $\left.T_{\text {milling bed }}\right)$ in the milling ball/grinding stock mixture with a thermocouple. The milling beakers were equipped with the respective number of milling balls; the grinding stock was added and milling was accomplished at the respective frequency, $v_{\mathrm{osc}}$, and milling time $t$. Afterward, the beaker was opened and the thermocouple placed in the middle of the beaker. The time for measurement was $<1 \mathrm{~min}$. If not stated otherwise, quartz sand was used as grinding stock in the basic experiments to avoid interference with mechanochemical reactions.

The following formulas were used for the calculation of the milling ball filling degree $\Phi_{\mathrm{MB}}$ and the grinding stock filling degrees $\Phi_{\mathrm{GS}}$ and $\Phi_{\mathrm{GS}}$, rel; with the milling ball volume $V_{\mathrm{MB}}$, the grinding stock bulk volume $V_{\mathrm{GS}}$, the vessel volume $V_{\mathrm{MV}}$, the diameter of the milling balls $d_{\mathrm{MB}}$, the number of milling balls $n_{\mathrm{MB}}$ and the porosity of the milling ball packing $\varepsilon$.

$$
\begin{aligned}
& \Phi_{\mathrm{MB}}=\frac{\sum V_{\mathrm{MB}}}{V_{\mathrm{MV}}}=\frac{1 / 6 \pi d_{\mathrm{MB}}^{3} n_{\mathrm{MB}}}{V_{\mathrm{MV}}}, \\
& \Phi_{\mathrm{GS}}=\frac{V_{\mathrm{GS}}}{V_{\mathrm{MV}}},
\end{aligned}
$$

$\Phi_{\mathrm{GS}, \text { rel }}=\frac{V_{\mathrm{GS}}(1-\varepsilon)}{V_{\mathrm{MV}} \Phi_{\mathrm{MB}} \varepsilon}$.

\section{Results and discussion}

The amount of heat that is dissipated is strongly dependent on the milling parameters that influence the energy input in the milling beaker. These parameters are the frequency $v_{\text {osc }}$, the milling ball diameter $d_{\mathrm{MB}}$, the milling ball filling degree $\Phi_{\mathrm{MB}}$ (Eq. 1), the milling beaker size, the grinding stock filling degree $\Phi_{\mathrm{GS}}$ (Eq. 2) and material properties of the grinding stock as well as of the grinding tools, such as Younǵs modulus, density, hardness and heat capacity $[12,26]$.

Temperature measurements at the surface and inside of the milling beaker showed that the temperature difference is negligible at low $v_{\text {osc }}$, but becomes larger for higher $v_{\text {osc }}$ ( $\Delta T$ up to $15 \mathrm{~K}$, Online resource 1 ). Temperatures recorded with surface measurements for example with temperature data loggers are therefore only an imprecise indicator for the internal temperature conditions [12]. A more precise, alternative method would be the temperature measurement inside the wall with embedded thermocouples [27], but even in this case a temperature gradient form the middle of the milling bed to the wall should occur.

For measurements on the surface, the thermocouple position was reported to be of slight influence [16]. We measured the temperature difference between the surface of the wall and the cap and found differences between 0.2 and $1.4 \mathrm{~K}$ (Online resources 1, 2). Thus, for further investigations, we determined the temperature inside the milling beaker $\left(T_{\text {milling bed }}\right)$ in the milling ball/grinding stock mixture with a thermocouple.

\section{Influence of the operating frequency $v_{\text {osc }}$}

The first investigated parameter was the operating frequency. As shown in Fig. 1, the temperature increased at $v_{\text {osc }}=15 \mathrm{~s}^{-1}$ within 90 min from 22 to $30{ }^{\circ} \mathrm{C}$. With higher $v_{\text {osc }}$, the heating rate as well as the final temperature was higher. Thus, at $v_{\mathrm{osc}}=30 \mathrm{~s}^{-1}$, a temperature of $87^{\circ} \mathrm{C}$ was measured. The energy that is dissipated at higher $v_{\text {osc }}$ is raised because of the higher kinetic energy of the milling balls. This led to an enhanced energy input.

\section{Influence of the milling ball filling degree}

Figure 2 illustrates the change in the temperature progression, if the milling ball filling degree $\Phi_{\mathrm{MB}}$ is varied. An increase of $\Phi_{\mathrm{MB}}$ from 0.06 to 0.36 resulted in a higher end temperature and heating rate, whereas the differences in 


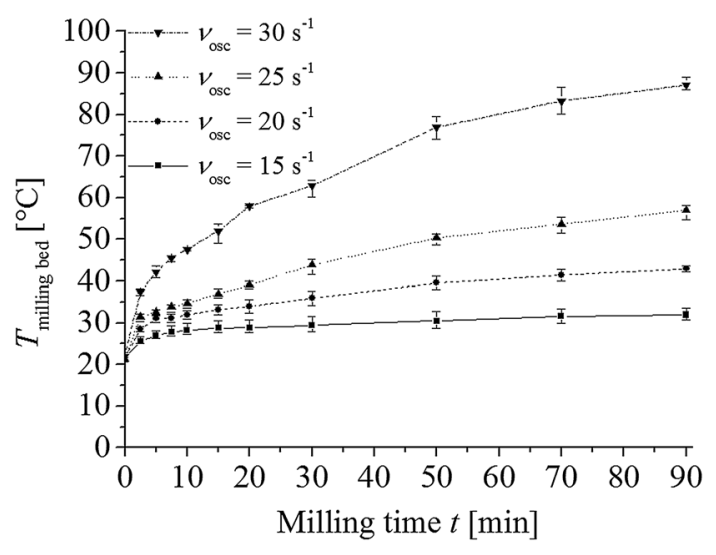

Fig. 1 Influence of the operating frequency on the temperature measured in the milling bed. Conditions: MBM MM400, $35 \mathrm{ml}$ steel beaker, steel balls, $d_{\mathrm{MB}}=5 \mathrm{~mm}, \Phi_{\mathrm{MB}}=0.24, m_{\text {quartz sand }}=15.36 \mathrm{~g}$ $\left(\Phi_{\mathrm{GS}}=0.31\right)$

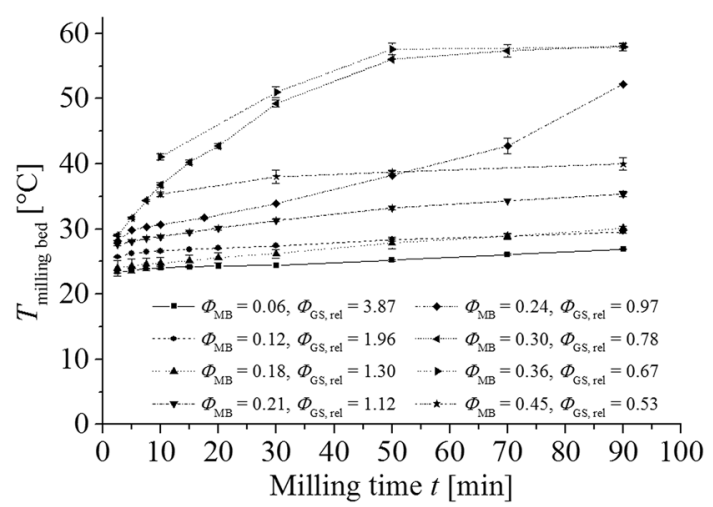

Fig. 2 Influence of the milling ball filling degree on the temperature measured in the milling bed. Conditions: MBM MM400, $v_{\mathrm{osc}}=20 \mathrm{~s}^{-1}$, $35 \mathrm{ml}$ steel beaker, steel balls, $d_{\mathrm{MB}}=5 \mathrm{~mm}, m_{\text {quartz }}$ sand $=7.48 \mathrm{~g}$ $\left(\Phi_{\mathrm{GS}}=0.15\right)$

$T_{\text {milling bed }}$ for $0.06 \leq \Phi_{\mathrm{MB}} \leq 0.18$ are small compared to experiments at higher filling degrees (for discussion, see next chapter). At $\Phi_{\mathrm{MB}}=0.45$, the temperature reached after $90 \mathrm{~min}$ was considerably reduced. For values of $\Phi_{\mathrm{MB}}<0.36$, the increase of milling balls number resulted in more ball-ball and ball-wall collisions and therefore led to a higher energy input and heat dissipation. The ball movement for $\Phi_{\mathrm{MB}}>0.36$ is hindered because of the reduced space for acceleration and less energy is dissipated, which justifies the lower final temperature [28, 29]. A similar result was reported by Fang et al. for the temperature that was generated in a lysis mill [30]. They observed the highest temperature if $60 \%$ of the beaker was filled with milling balls, which approximately corresponds to $\Phi_{\mathrm{MB}}$ of 0.4. A higher heating rate was also found with an increased number of milling balls in a Spex mixer mill [13]. The observed dependency of the temperature from $\Phi_{\mathrm{MB}}$ is also in good agreement with experimental results for the reaction of vanillin and barbituric acid in an MBM, in which the yield increased for $0.06<\Phi_{\mathrm{MB}}<0.30$ and strongly decreased at $\Phi_{\mathrm{MB}}=0.45$ [24]. This indicates the influence of the temperature on an organic reaction in a ball mill and the demand for a temperature control for organic syntheses in ball mills.

Interestingly, if $\Phi_{\mathrm{MB}}$ was changed from 0.21 to 0.3 , a huge difference in the measured heating curve was observed. As the amount of grinding stock was kept constant at $\Phi_{\mathrm{GS}}=0.15$, we calculated $\Phi_{\mathrm{GS}}$, rel (Eq. 3) defined as the grinding stock filling degree with regard to the void volume in the milling ball packing. The complete void volume is filled with the grinding stock if $\Phi_{\mathrm{GS}}$, rel $=1$. Results show that the change in the heat up curve occurs if $\Phi_{\mathrm{GS}}$, rel is approximately at this value. The milling beakers warm up significantly slower for $\Phi_{\mathrm{GS}}$, rel $>1$ (see Online resource 1). The grinding stock overfills the void volume, the velocity of the milling balls is reduced and thus less heat is generated.

\section{Influence of the grinding stock filling degree}

Next, we varied $\Phi_{G S}$ at a constant $\Phi_{\mathrm{MB}}$ (Fig. 3). The highest end temperature of $77^{\circ} \mathrm{C}$ was measured without any grinding stock. By adding even small amounts of quartz sand, the temperature decreased considerably [13]. The grinding stock influences the elasticity of the collisions; the velocity and motion of the milling balls are reduced and as a consequence less energy is dissipated as heat [29]. Thus, with grinding stock a "damping effect" can be observed. The grinding stock acts as a heat sink as the energy is dissipated in more material and the average temperature of the milling bed is lower. Furthermore, the convection of heat from the milling balls to the milling beaker wall is improved if a grinding stock is loaded, as the main mechanism for heat transfer between a moving ball

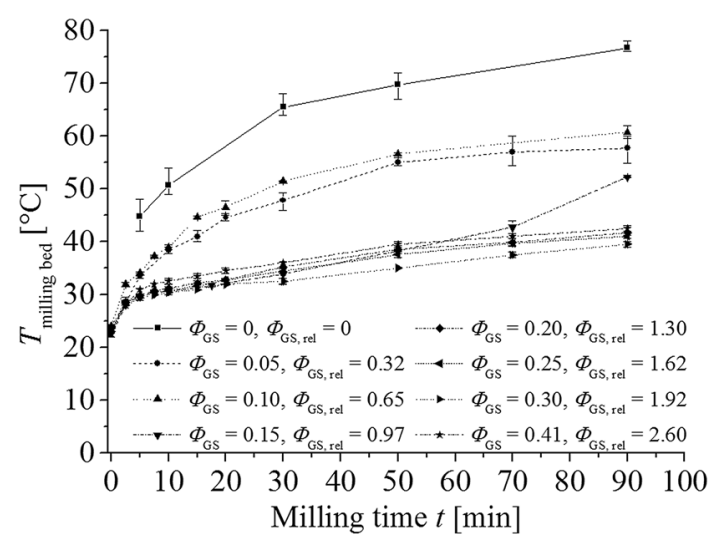

Fig. 3 Influence of the grinding stock filling degree on the temperature measured in the milling bed. Conditions: MBM MM400, $v_{\mathrm{osc}}=20 \mathrm{~s}^{-1}, 35 \mathrm{ml}$ steel beaker, steel balls, $d_{\mathrm{MB}}=5 \mathrm{~mm}$, $\Phi_{\mathrm{MB}}=0.24$, quartz sand 
and the wall is forced convection [5]. As observed for the variation of $\Phi_{\mathrm{MB}}$ (see Fig. 2), a significant change in the heating curve was observed if $\Phi_{G S}$ was varied. Temperatures obtained for $\Phi_{\mathrm{GS}} \geq 0.20$ are nearly in the same range, independent of $\Phi_{\mathrm{GS}}$, but considerably higher temperatures were measured if $\Phi_{\mathrm{GS}}$ is equal or smaller than 0.15 . The point of change is, as observed in the investigation of $\Phi_{\mathrm{MB}}$ (Fig. 2), if $\Phi_{\mathrm{GS}}$, rel reaches a value of 1.0 (Online resource $1)$. Thus, the effect of the amount of grinding stock on the temperature is little for values of $\Phi_{\mathrm{GS}}$, rel $>1\left(\Phi_{\mathrm{GS}} \geq 0.20\right)$. Obviously, a further addition of grinding stock to the milling balls has a negligible effect on the temperature progression in the milling bed. A similar effect was found for changing $\Phi_{\mathrm{MB}} \geq 0.20$ as shown in Fig. 2, which indicates a less pronounced temperature increase for $1.3 \leq \Phi_{\mathrm{GS}}$, rel $\leq 3.87\left(0.18 \leq \Phi_{\mathrm{MB}} \leq 0.06\right)$, similar to the results summarized in Fig. 3.

\section{Influence of the milling ball and milling beaker material}

The material of the milling balls is an important factor for the energy input in the milling beaker. We performed reactions with milling balls made of steel $\left(\rho=7.8 \mathrm{~g} \mathrm{~cm}^{-1}\right)$, zirconium oxide $\left(\rho=5.9 \mathrm{~g} \mathrm{~cm}^{-1}\right)$, sintered corundum $\left(\rho=3.8 \mathrm{~g} \mathrm{~cm}^{-1}\right)$, silicon nitride $\left(\rho=3.25 \mathrm{~g} \mathrm{~cm}^{-1}\right)$ and agate $\left(\rho=2.65 \mathrm{~g} \mathrm{~cm}^{-1}\right)$. From Fig. 4 , it becomes clear that the higher the density of the milling balls, the higher is the temperature. A linear increase with the density of the milling balls was found. Milling balls made of a high density material are heavier. Thus, the kinetic energy of the milling balls is elevated. This led to a higher energy that is provided in the collision.

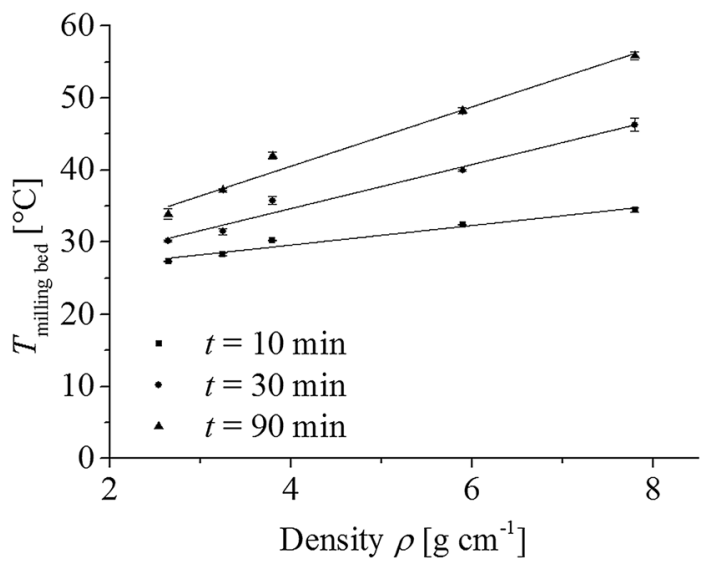

Fig. 4 Influence of the milling ball density on the temperature measured in the milling bed. Conditions: MBM MM400, $v_{\mathrm{osc}}=20 \mathrm{~s}^{-1}$, $35 \mathrm{ml}$ steel beaker, $d_{\mathrm{MB}}=10 \mathrm{~mm}, \Phi_{\mathrm{MB}}=0.24, m_{\text {quartz sand }}=7.48 \mathrm{~g}$ $\left(\Phi_{\mathrm{GS}}=0.15\right)$
The milling beaker material affects the temperature of the milling beakers as well. The temperature in zirconium oxide milling beakers was approximately $6 \mathrm{~K}$ higher as in steel beakers (with zirconium oxide balls in both types of milling beakers) because of the lower thermal conductivity of zirconium oxide.

\section{Influence of the milling ball diameter}

As shown in Fig. 5, the final temperature depends on $d_{\mathrm{MB}}$ : $T_{\text {milling bed }}$ passes through a maximum for $7 \mathrm{~mm}$ balls. Milling balls with lower or larger diameter led to a reduced dissipation of heat. Aside from density and number, the diameter of the milling balls can affect the energy dissipation, because larger milling balls correspond to a higher kinetic energy of the single balls. However, the number of milling balls is affected if $\Phi_{\mathrm{MB}}$ is kept constant, which influences the number of collisions [24]. In addition, $d_{\mathrm{MB}}$ affects the friction coefficient and the frictional energy [31]. The results are in consensus with data published by Kwon et al. for mechanical alloying, who reported elevated temperatures in planetary ball mills if $d_{\mathrm{MB}}$ was increased from 3 to $9 \mathrm{~mm}$, but a decreased temperature for larger milling balls [5]. In contrast, Takacs reported that the final temperature was relatively independent of the number and size of the milling balls [13]. For milling with a constant number of milling balls, a higher temperature can be assumed for larger milling balls (as long as $\Phi_{\mathrm{MB}}$ is not too high) because of the higher kinetic energy with higher $d_{\mathrm{MB}}$. For instance, the temperature increase for milling with three balls with a diameter of $10 \mathrm{~mm}$ resulted in a temperature increase of $3 \mathrm{~K}$ after $30 \mathrm{~min}$, whereas with $15 \mathrm{~mm}$ balls $\Delta T$ was $20 \mathrm{~K}$.

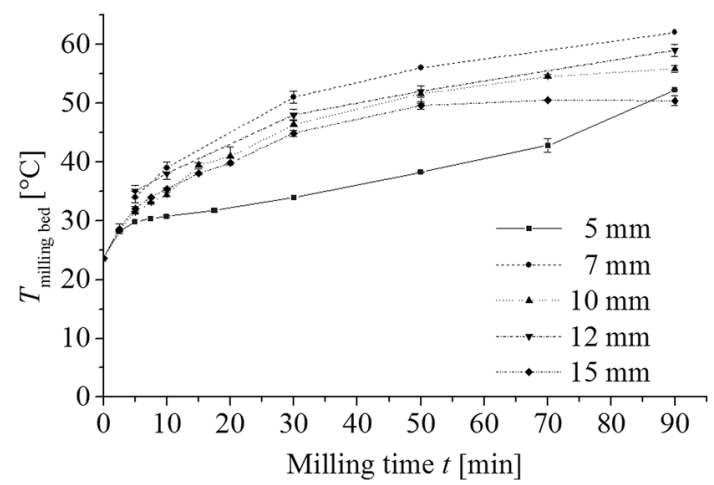

Fig. 5 Influence of the milling ball diameter on the temperature measured in the milling bed. Conditions: MBM MM400, $v_{\mathrm{osc}}=20 \mathrm{~s}^{-1}$, $35 \mathrm{ml}$ steel beaker, steel balls, $\Phi_{\mathrm{MB}}=0.24, m_{\text {quartz }}$ sand $=7.48 \mathrm{~g}$ $\left(\Phi_{\mathrm{GS}}=0.15\right)$ 


\section{Variations of the milling beaker dimension}

Experiments in milling beakers with varied volume revealed that the size of the milling beaker has a strong influence on the temperature (Online resource 1). While in $10 \mathrm{ml}$ beakers after $90 \mathrm{~min}$ a temperature of $35^{\circ} \mathrm{C}$ was observed, $T_{\text {milling bed }}$ was 52 and $58{ }^{\circ} \mathrm{C}$ in 35 and $50 \mathrm{ml}$ beakers, respectively. On the one hand, the number of milling balls is higher in larger milling beakers, which results in an increased number of collisions and therefore a higher energy input. On the other hand, the larger milling beakers have a lower volume to surface ratio. The ratio is 1.45 times lower for $50 \mathrm{ml}$ beakers as for $10 \mathrm{ml}$ beakers. Thus, the energy dissipation from the beaker to the environment is slower, resulting in a higher $T_{\text {milling bed. }}$

\section{Influence of the grinding stock material}

The temperature that was measured after 90 min milling strongly depends on the loaded material. The highest temperature was measured without any grinding stock (compare section grinding stock filling degree, Fig. 3). The addition of powder led to lower temperatures in every case. The temperature ranges between 40 and $63{ }^{\circ} \mathrm{C}$ for quartz sand and vanillin, respectively (Online resource 1 ). The material influence on the temperature seems to be a complicated interaction of material properties like Younǵs modulus and hardness [13]. The kind of material influences the elasticity of the collision and the motion of the balls, as shown for planetary ball mills [32]. Thus, it acts on the temperature progression and on the heat transfer from the balls to the wall of the beaker [13]. Younǵs modulus for example is insufficient to describe the increase of temperature. For example, with $\mathrm{MgF}_{2}$ and $\mathrm{CaF}_{2}$ as grinding stocks, final temperatures of $51^{\circ} \mathrm{C}$ were measured, although Young's modulus is considerably different with 139 and $76 \mathrm{GPa}$, respectively [33]. In addition to the material properties of the grinding stock, physical phenomena like the compaction of the material on the milling wall influence $T_{\text {milling bed. }}$ If the grinding stock material adheres to the wall, less material is trapped when the balls collide. Furthermore, the compact layers reduce the free space for acceleration of the balls.

Several grinding stock materials were examined at constant $\Phi_{G S}$ or constant mass. The trend of the end temperatures was similar for both conditions (Online resource 1). Material properties seem to have strong influence, balancing the changes in the grinding stock filling degree.

In Table 1 shows the maximal observed temperature difference that was obtained by variation of one parameter, while other parameters were kept constant. In the investigated range, the effect of the operating frequency was highest. A temperature difference of roughly $55 \mathrm{~K}$ was detected
Table 1 Maximal measured temperature difference obtained by variation of one parameter

\begin{tabular}{ll}
\hline Condition & $\Delta T_{\max -\min }(\mathrm{K})$ \\
\hline$v_{\text {osc }}$ & 55.1 \\
Changed $\Phi_{\mathrm{GS}}$ & 37.3 \\
Changed $\Phi_{\mathrm{MB}}$ & 31.2 \\
Beaker size & 23.9 \\
Grinding stock material $\left(\Phi_{\mathrm{GS}}=\right.$ const. $)$ & 23.5 \\
Grinding tool material & 22 \\
Grinding stock material $\left(m_{\mathrm{GS}}=\right.$ const. $)$ & 13 \\
$d_{\mathrm{MB}}$ & 11.6 \\
\hline
\end{tabular}

between milling at the lowest and highest operating frequency. By variation of the filling degree of the grinding stock as well as of the milling balls, huge values for $\Delta T_{\max -\min }$ could be found. The impacts of the beaker size, grinding stock material and grinding tool material were at the same level with approximately $23 \mathrm{~K}$. The lowest effect was observed for changes in the grinding stock material (at constant $m_{\mathrm{GS}}$ ) and for the milling ball diameter. Thus, the highest effects were induced by $v_{\text {osc }}$ and the filling degree, which is important with regard to the design of the experiments.

\section{Conclusion}

The measurement of the temperature that was generated in a mixer ball mill indicates a strong dependence of $T_{\text {milling bed }}$ on several milling parameters. Higher temperatures were measured with increased operating frequency and in milling beakers with larger volume. The heat dissipation passes through a maximum for the milling ball filling degree and the milling ball diameter. Regarding the milling ball material, a linear correlation to the density of the milling balls was found. The results indicate that $\Phi_{\mathrm{GS}}$, rel is of great influence on the temperature progression. A changed behavior was observed if $\Phi_{\mathrm{GS}}$, rel was increased over $\Phi_{\mathrm{GS} \text {, rel }}=1$. These results can be helpful for the experimental design and for performing reactions in ball mills successfully. Furthermore, the results seem to be transferrable to other types of ball mills (for example, planetary ball mills) and are not restricted to the investigated type of mixer ball mills.

Acknowledgments This work was funded by the Deutsche Bundesstiftung Umwelt (DBU; AZ 29622-31).

Open Access This article is distributed under the terms of the Creative Commons Attribution 4.0 International License (http://creative commons.org/licenses/by/4.0/), which permits unrestricted use, distribution, and reproduction in any medium, provided you give appropriate credit to the original author(s) and the source, provide a link to the Creative Commons license, and indicate if changes were made. 


\section{References}

1. Wang GW (2013) Mechanochemical organic synthesis. Chem Soc Rev 42(18):7668-7700. doi:10.1039/C3CS35526H

2. Zhu SE, Li F, Wang GW (2013) Mechanochemistry of fullerenes and related materials. Chem Soc Rev 42(18):7535-7570. doi:10. 1039/C3CS35494F

3. Stolle A, Szuppa T, Leonhardt SES, Ondruschka B (2011) Ball milling in organic synthesis: solutions and challenges. Chem Soc Rev 40(5):2317-2329. doi:10.1039/C0cs00195c

4. Stolle A, Ranu B (eds) (2015) Ball milling towards green synthesis: applications, projects, challenges. The Royal Society of Chemistry, Cambridge. doi:10.1039/9781782621980

5. Kwon YS, Gerasimov KB, Yoon SK (2002) Ball temperatures during mechanical alloying in planetary mills. J Alloys Compd 346(1-2):276-281. doi:10.1016/S0925-8388(02)00512-1

6. Naimi-Jamal MR, Mokhtari J, Dekamin MG, Kaupp G (2009) Sodium tetraalkoxyborates: intermediates for the quantitative reduction of aldehydes and ketones to alcohols through ball milling with NaBH4. Eur J Org Chem 21:3567-3572. doi:10. 1002/ejoc.200900352

7. Gérard EMC, Sahin H, Encinas A, Bräse S (2008) Systematic study of a solvent-free mechanochemically induced domino oxaMichael-Aldol reaction in a ball mill. Synlett 17:2702-2704. doi:10.1055/s-0028-1067255

8. Kaupp G (2003) Solid-state molecular syntheses: complete reactions without auxiliaries based on the new solid-state mechanism. CrystEngComm. doi:10.1039/B303432a

9. Tan YJ, Zhang Z, Wang FJ, Wu HH, Li QH (2014) Mechanochemical milling promoted solvent-free imino DielsAlder reaction catalyzed by $\mathrm{FeCl} 3$ : diastereoselective synthesis of cis-2,4-diphenyl-1,2,3,4-tetrahydroquinolines. RSC Adv 4(67): 35635-35638. doi:10.1039/C4RA05252H

10. Yu J, Li Z, Jia K, Jiang Z, Liu M, Su W (2013) Fast, solvent-free asymmetric alkynylation of prochiral $\mathrm{sp} 3 \mathrm{C}-\mathrm{H}$ bonds in a ball mill for the preparation of optically active tetrahydroisoquinoline derivatives. Tetrahedron Lett 54(15):2006-2009. doi:10.1016/j. tetlet.2013.02.007

11. Colacino E, Nun P, Colacino FM, Martinez J, Lamaty F (2008) Solvent-free synthesis of nitrones in a ball-mill. Tetrahedron 64(23):5569-5576. doi:10.1016/j.tet.2008.03.091

12. McKissic KS, Caruso JT, Blair RG, Mack J (2014) Comparison of shaking versus baking: further understanding the energetics of a mechanochemical reaction. Green Chem 16(3):1628-1632. doi:10.1039/C3gc41496e

13. Takacs L, McHenry JS (2006) Temperature of the milling balls in shaker and planetary mills. J Mater Sci 41(16):5246-5249. doi:10.1007/s10853-006-0312-4

14. Tullberg E, Peters D, Frejd T (2004) The Heck reaction under ball-milling conditions. J Organomet Chem 689(23):3778-3781. doi:10.1016/j.jorganchem.2004.06.045

15. Jiang XJ, Trunov MA, Schoenitz M, Dave RN, Dreizin EL (2009) Mechanical alloying and reactive milling in a high energy planetary mill. J Alloys Compd 478(1-2):246-251. doi:10.1016/j. jallcom.2008.12.021

16. Takacs L (2002) Self-sustaining reactions induced by ball milling. Prog Mater Sci 47(4):355-414. doi:10.1016/S0079-6425(01) 00002-0

17. Meine N, Rinaldi R, Schüth F (2012) Solvent-free catalytic depolymerization of cellulose to water-soluble oligosaccharides. ChemSusChem 5(8):1449-1454. doi:10.1002/cssc.201100770
18. Rodriguez B, Bruckmann A, Bolm C (2007) A highly efficient asymmetric organocatalytic aldol reaction in a ball mill. Chem Eur J 13(17):4710-4722. doi:10.1002/chem.200700188

19. Retsch CryoMill (2015) http://www.retsch.com/products/milling/ ball-mills/mixer-mill-cryomill/function-features. Accessed 22 June 2015

20. Retsch Emax (2015) http://www.retsch.com/products/milling/ ball-mills/emax/function-features. Accessed 22 June 2015

21. He S, Qin Y, Walid E, Li L, Cui J, Ma Y (2014) Effect of ballmilling on the physicochemical properties of maize starch. Biotechnol Rep 3:54-59. doi:10.1016/j.btre.2014.06.004

22. Immohr S, Felderhoff M, Weidenthaler C, Schüth F (2013) An orders-of-magnitude increase in the rate of the solid-catalyzed $\mathrm{CO}$ oxidation by in situ ball milling. Angew Chem Int Ed 52(48):12688-12691. doi:10.1002/anie.201305992

23. Kaupp G, Naimi-Jamal MR, Schmeyers J (2002) Quantitative reaction cascades of ninhydrin in the solid state. Chem Eur $\mathrm{J}$ 8(3):594-600. doi:10.1002/1521-3765(20020201)8:3<594:AidChem594>3.0.Co;2-5

24. Schmidt R, Burmeister CF, Baláž M, Kwade A, Stolle A (2015) Effect of reaction parameters on the synthesis of 5-arylidene barbituric acid derivatives in ball mills. Org Process Res Dev 19(3):427-436. doi:10.1021/op5003787

25. Etman HA, Metwally HM, Elkasaby MM, Khalil AM, Metwally MA (2011) Green, two components highly efficient reaction of ninhydrin with aromatic amines, and malononitrile using ballmilling technique. Am J Org Chem 1:10-13. doi:10.5923/j.ajoc. 20110101.03

26. Yazdani A, Hadianfard MJ, Salahinejad E (2013) A system dynamics model to estimate energy, temperature, and particle size in planetary ball milling. J Alloys Compd 555:108-111. doi:10.1016/j.jallcom.2012.12.035

27. Strukil V, Fabian L, Reid DG, Duer MJ, Jackson GJ, EckertMaksic M, Friscic T (2010) Towards an environmentally-friendly laboratory: dimensionality and reactivity in the mechanosynthesis of metal-organic compounds. Chem Commun 46(48):9191-9193. doi:10.1039/C0cc03822a

28. Sato A, Kano J, Saito F (2010) Analysis of abrasion mechanism of grinding media in a planetary mill with DEM simulation. Adv Powder Technol 21(2):212-216. doi:10.1016/j.apt.2010.01.005

29. Burmeister CF, Kwade A (2013) Process engineering with planetary ball mills. Chem Soc Rev 42(18):7660-7667. doi:10. 1039/C $3 \operatorname{cs} 35455 \mathrm{e}$

30. Fang Y, Salame N, Woo S, Bohle DS, Friscic T, Cuccia LA (2014) Rapid and facile solvent-free mechanosynthesis in a cell lysis mill: preparation and mechanochemical complexation of aminobenzoquinones. CrystEngComm 16(31):7180-7185. doi:10. 1039/C4CE00328D

31. Köster A, Scherge M, Teipel U (2014) Energy distributions of grinding balls in frictional contact. Chem Ing Tech 86(3):361-364. doi:10.1002/cite.201300127

32. Rosenkranz S, Breitung-Faes S, Kwade A (2011) Experimental investigations and modelling of the ball motion in planetary ball mills. Powder Technol 212(1):224-230. doi:10.1016/j.powtec. 2011.05.021

33. Korth Kristalle. http://www.korth.de/index.php/material-161. html. Accessed 2015/03/16 